\title{
Marketing político-territorial en el espacio público y en la política de vivienda social de la Revolución Bolivariana. El caso de Venezuela
}

Political marketing in the public space and in the social housing policy of the Bolivarian Revolution. The case of Venezuela

\section{Historial del artículo}

Recibido:

26 de abril de 2021

Revisado

31 de mayo de 2021

Aceptado:

16 de junio de 2021

\section{Yaneira Wilson Wetter ${ }^{\mathrm{a}}$}

a École Nationale Supérieure d'Architecture de Paris-Val de Seine. Centre de Recherche sur l'Habitat (CRH) - LAVUE - CNRS UMR 7218 - France. Correo electrónico: yaneira.wilson@paris-valdeseine.archi.fr ORCID: https://orcid.org/0000-0003-3730-2224

\section{Palabras clave} Marketing político y territorial, muralismo político, política pública, vivienda social

\section{Keywords}

Political and territorial marketing, political muralism, public policy, social housing

\section{Resumen}

El proyecto Gran Misión Vivienda Venezuela (GMVV) propone desde el año 2011 la construcción de cinco millones de viviendas con la meta de finalizar en el 2025. Luego de las fuertes lluvias, recurrentes en el país, miles de personas perdieron sus hogares y esta situación se ha repetido y acumulado con los años. En este contexto de caos se excluyó cualquier tipo de planificación, la atmósfera de emergencia requirió la construcción expedita de millones de viviendas excluyendo en la mayoría de los casos la coherencia con el entorno en que se insertaron los proyectos o incluso variables de orden técnico y estético. El objetivo de este artículo es crear una lectura de un marketing político territorial a través de la arquitectura y de la producción de ciertas imágenes, alegóricas de una demagogia hoy día en Venezuela. La metodología se apoya en la sociología visual, luego de un trabajo de campo que comprendió el análisis de más de 20 operaciones y 50 entrevistas a diversos actores involucrados en esta producción.

\begin{abstract}
Since 2011, the Gran Misión Vivienda Venezuela (GMVV) project has proposed the construction of five million homes with the goal of finishing by 2025. After heavy rains, recurrent in the country, thousands of people lost their homes, and this situation has been repeated and accumulated over the years. In this context of chaos, any kind of planning was excluded, the emergency atmosphere required the expeditious construction of millions of houses excluding in most cases the coherence with the environment in which the projects were inserted or even technical and aesthetic variables. The objective of this article is to create a reading of a territorial political marketing through architecture and the production of certain images, allegorical of a demagogy today in Venezuela. The methodology is based on visual sociology, after a fieldwork that included the analysis of more than 20 operations and 50 interviews with various actors involved in this production.
\end{abstract}




\section{Introducción}

Desde Hugo Chávez ${ }^{1}$ hasta el actual gobierno de Nicolás Maduro $^{2}$, Venezuela ha iniciado a partir de 1999 una serie de reformas destinadas al socialismo del siglo XXI, suponiendo resolver los errores del "socialismo real" encarnado por el símbolo del "hombre nuevo" de la Revolución Bolivariana. Transformado, el país ha visto desmanteladas sus políticas públicas a favor de nuevos mecanismos, las Misiones, que, desde la agricultura a la vivienda, pasando por la educación y la salud, respaldan los programas sociales de lucha contra la pobreza para responder a la emergencia social, para remediar retrasos administrativos y la falta de respuesta adecuadas de parte de los gobiernos anteriores. Las mismas fueron legalmente constituidas en el 2014 (Decreto $\mathrm{N}^{\circ}$ 1934) bajo el título "Sistema Nacional de Misiones, Grandes Misiones y Micro-Misiones «Hugo Chávez»". La particularidad es que, mediante un movimiento democrático-participativo se establezca un nuevo "Poder Popular" que promueva al pueblo como principal ejecutor, y cuyo fin sea la constitución de formas de autogobierno comunitario, denominadas Consejos Comunales y Comunas por parte de los habitantes.

La más importante de estas Misiones, la Gran Misión Vivienda Venezuela (GMVV), lanzada en $2011^{3}$, propone la construcción masiva en todo el territorio nacional de 5 millones de viviendas para culminarlas en el 2025 . Esta planificación va acompañada, según declaraciones públicas posteriores del ministro de Planificación entre 1999 y 2014, Jorge Giordani (2014), de un gasto excesivo de recursos financieros que contribuyó a acentuar la crisis económica cuando esta comenzó a sentirse en el país. La crisis se ha agravado desde 2014 por la caída de los precios del petróleo, de los que depende en gran medida la economía. Entre 2012 y 2018, la inflación se disparó y el PIB cayó dos tercios, mientras que más de 4,6 millones de los 30 millones de habitantes del país ya han emigrado, según el Alto Comisionado de las Naciones Unidas para los refugiados.

Este artículo analiza esta política habitacional productivista GMVV, cuya particularidad es movilizar una estética singular y un "marketing político y territorial" que transmite símbolos ideológicos visibles sobre el terreno. A través de un enfoque social y urbano se mostrará el modo de producción y la arquitectura de esta construcción masiva de viviendas, las diversas representaciones y el impacto de estas en los habitantes a través del proyecto Gran Misión Vivienda Venezuela (GMVV). La explotación gráfica de la firma y los "Ojos de Chávez" (Figura 1) marcan fuertemente la geografía urbana en Venezuela. Incluso observaremos algunos instrumentos territoriales o la proposición de un título de propiedad colectiva forman parte de esta nueva representación de socialismo del siglo XXI que está en curso.

Las preguntas principales y que formarán parte del esquema del texto son: ¿cómo, en este contexto político y socioeconómico, el Estado ha desarrollado este programa de producción de viviendas sociales? ¿La arquitectura y el tipo de edificios propuestos se corresponden con el ideal del socialismo del siglo XXI? ¿Cómo afecta a la gestión y ordenación del territorio? ¿En qué medida este programa se inscribe en el terreno y propone nuevos instrumentos que respondan al cambio de los modos de vida de los habitantes?

Para responder a estas preguntas, este capítulo está estructurado en cuatro partes. En primer lugar, esbozaremos las nociones de imagen y representación para entender la creación del marketing territorial y político a través de esta política pública. La segunda parte propone explicar el contexto geográfico y político y los fundamentos de la noción de participación y un tipo de gobernabilidad para comprender mejor el origen de las Misiones y de la GMVV. Una tercera parte estará dedicada a comprender el modelo de construcción, los actores involucrados y la recepción por parte de los habitantes. En una cuarta, y última parte, analizaremos la mercadotecnia política y territorial, la influencia de las campañas presidenciales, la interacción que esta produce en la geografía urbana pasando por las nociones de identidad y de propiedad producidas. El objetivo final será dar una lectura de la actual producción y reproducción frecuente de ciertas imágenes, alegoría de una demagogia a través de la arquitectura o el urbanismo reciente en Venezuela, así como el efecto de la

\footnotetext{
${ }^{1}$ Hugo Rafael Chávez Frías (1954-2013) es un militar y hombre de Estado, presidente de Venezuela (1999-2013). Pretendiendo ser bolivariano y teniendo como objetivo la instauración del socialismo del siglo XXI, pone en marcha un conjunto de reformas, conocidas con el nombre de "Revolución bolivariana", que incluyen la promulgación de una nueva constitución, una política de "democracia participativa". y la nacionalización de industrias clave. Nicolás Maduro, sindicalista y hombre de Estado venezolano, presidente de Venezuela desde el 2013.

${ }^{2}$ Sindicalista y hombre de estado venezolano, presidente de Venezuela desde el 2013.

${ }^{3}$ Inicialmente el proyecto proponía la construcción de 300.000 viviendas cada año, durante diez años por un parque de viviendas nacional estimada en ese momento en 8,2 millones de viviendas.
} 

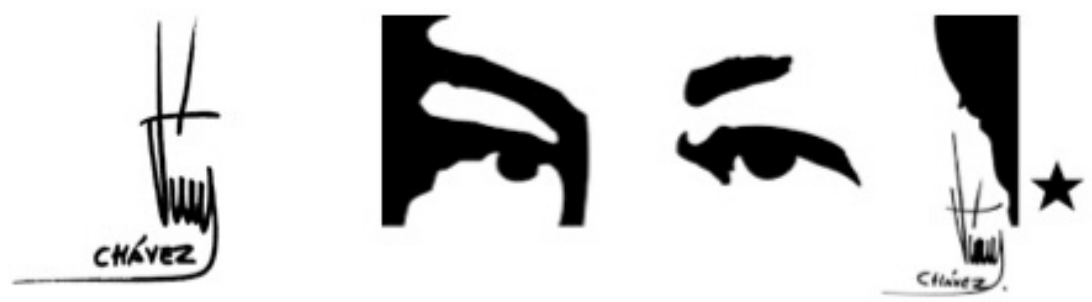

Figura 1. Imágenes Firma de Chávez y "Ojos de Chávez". Fuente: CC BY-SA 2.0.

imagen producida como propaganda en las operaciones urbanas GMVV o en el espacio público.

\section{Materiales y métodos}

A nivel metodológico, se ha constituido un material de terreno a lo largo de los años (2015-2020) que cuenta en total 24 entrevistas guiadas por el cuestionario a habitantes de la GMVV, 15 entrevistas realizadas con expertos, 12 entrevistas abiertas a investigadores y técnicos (principalmente la Fundación Misión Hábitat y el Instituto Urbanismo de Caracas). La constitución de un cuerpo de análisis a partir del análisis de 2 ciudades socialistas y 23 operaciones GMVV (Figura 2) acompañado de una compilación de más de mil fotografías tomadas durante las distintas visitas (edificios GMVV, espacios públicos, así como a habitantes y expertos o técnicos). La participación al Foro "Realidades y Perspectivas para fortalecer el Hábitat Comunal"4 que celebraba los cinco años de la construcción GMVV me permitió entrevistar gran parte de los actores institucionales y consolidar aún más el grupo de entrevistas a realizar. Finalmente, para poner en diálogo las cifras oficiales con la realidad sobre el terreno, se incluyeron datos del informe (2018) realizado por la ONG Programa de Educación-Acción en Derechos Humanos (Provea), así como el informe de la Cámara Venezolana de la Construcción (CVC) "Propuesta para la Venezuela que queremos" (2017). Con el fin de simplificar este análisis enmarcado en la disciplina de la sociología visual o sociología en imágenes ${ }^{5}$, nos concentramos en la Gran Caracas y más precisamente en tres áreas de estudio: Estado La Guaira, Ciudad Caribia y distintas operaciones en el centro de Caracas, principalmente en el Municipio Libertador.

La mirada del investigador social es la mirada cartesiana que va más allá del fenómeno para encontrar la esencia de las relaciones sociales. En la sociología visual el investigador emplea imágenes como fuente de datos, se centra en la imagen como instrumento de investigación de las relaciones sociales. (Ortega Olivares, 2017, p. 167)

Este enfoque se centra en el "objeto-imagen", en este sentido, es sobre todo una metodología para la lectura, descripción y comentario de la imagen al servicio de un objeto de estudio, en este caso alrededor de la producción de la vivienda social. Lo que nos interesa de este trabajo sobre la imagen en particular es la búsqueda activa de "pistas capaces de revelar muchos detalles de la vida social" (Piette, 2007, p. 23).

Del concepto de imagen, representación al marketing político en la ciudad

La primera acepción de la palabra imagen, según el diccionario Le Robert, remonta a 1170 y la define como: "la reproducción invertida que una superficie pulida da

4 El foro público proponía hacer balance de los primeros cinco años de construcción de la GMVV, patrocinado por el Ministerio del Poder Popular para la Vivienda y Hábitat, el que se llevó a cabo los días 3, 4 y 5 de agosto 2016, en la sede de Petróleos de Venezuela de PDVSA en Caracas. En este foro participaron arquitectos de gran renombre como el Dr. Juan Pedro Posani, el Dr. Newton Rauseo y el Dr. Fruto Vivas. También al arquitecto Juan Carlos Rodríguez del Campamento de Pioneros.

5 Este concepto se utiliza cada vez más desde finales de los años 1990 y al principio del año 2000, un grupo de investigadores coinciden que la sociología visual conlleva en algunas oportunidades un riesgo de confusión entre los sentidos (vista), el objeto percibido (visible o visto), y los dispositivos de visualización que permiten a la vista ejercitarse sobre el objeto percibido. Estos tres aspectos también han sido claramente identificados por Wagner (2006), retomado por Du \& Meyer (2008) a través de los términos "visual", "visible" y "visualizado" (Chauvin \& Reix, 2015, p.15). Más recientemente, Maresca \& Meyer (2013) añadieron una tercera distinción introduciendo la idea de "sociología en imágenes" cuando esta sirve precisamente como medio de restitución al análisis sociológico. Y de acuerdo con la conclusión de ese texto, de hecho, legitima el uso de imágenes como datos que podrían utilizarse, analizarse y científicamente restaurarse de la misma manera que las palabras y los números, que se unirán en diferentes tipos de sociología visual. 


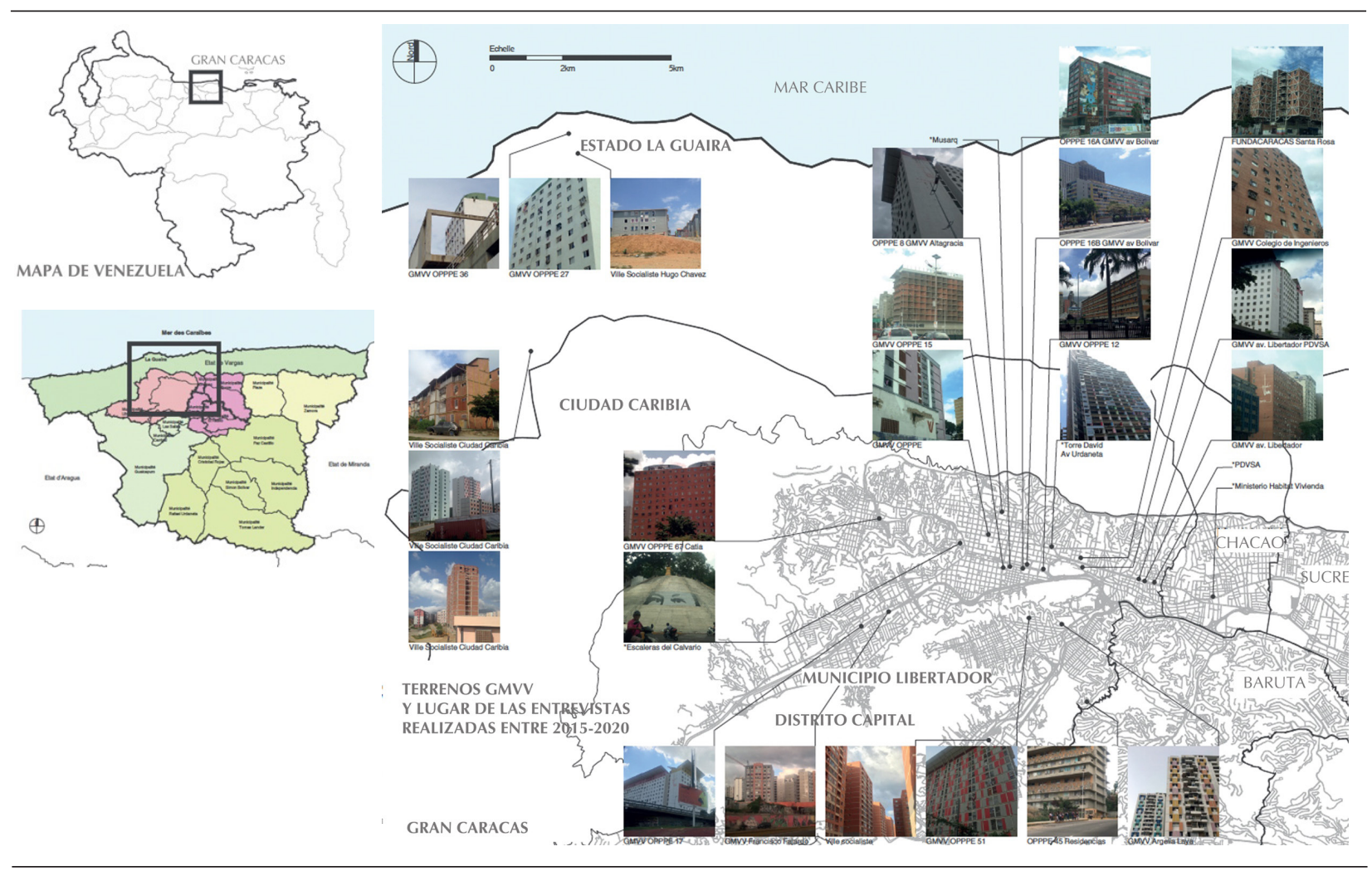

Figura 2. Ubicación y coordenadas geográficas del área de estudio que incluye el Estado La Guaira 10³6'38"N 664 $44^{\prime} 06^{\prime \prime W}$,

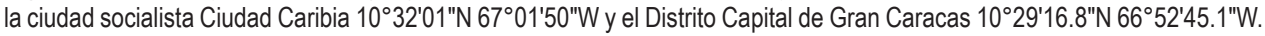
Fuente: las fotografías corresponden a las operaciones analizadas y a los espacios analizados en este estudio (elaboración propia, 2020).

de un objeto reflejado en ella". La segunda, citada en 1597, es: "reproducción exacta o analógica de un ser, de una cosa" y solo en el siglo XVI esta palabra designa la "representación mental de origen sensible" (Bernard, 2010). Etimológicamente, la imagen es lo que imita, "lo que toma el lugar de", lo que sustituye; mientras que el significado latín designa la estatua. Poner una imagen es, pues, inmovilizar, congelar y mirar una cosa en el lugar de otra.

Etimológicamente, igual según el diccionario, la palabra representación significa "la acción de poner ante los ojos", es decir, mostrar algo que está ausente; en el ámbito de la filosofía, significa revelar una idea aproximada y temporal de la realidad de un objeto concreto: en este caso, la vivienda social, la política del actual Estado venezolano y la percepción de los habitantes. Según la definición del geógrafo francés M. Roncayolo, la representación de la ciudad no es individual, sino colectiva:

[s]i la ciudad es por excelencia (en su versión clásica) el lugar de la división social del trabajo, del intercambio, del encuentro y del poder, de la 'religión' en el sentido etimológico del término, en definitiva, de la sociabilidad, toda representación es ciertamente representación de lo colectivo y representación colectiva. (Chesneau, 2011, p. 406)

La representación es un desarrollo de ideas y percepciones individuales o colectivas que abordan cuestiones políticas, económicas, culturales y sociales. Esta representación con respecto a la vivienda social ocupa un lugar importante entre los habitantes, pero depende del espacio que se le dé para expresarse, ya sea en un marco institucional a través de las políticas públicas, a través de la forma de gobernar o en la reutilización de los lugares habitados. Finalmente, la dialéctica socioespacial implica que las estructuras espaciales y sociales son factores mutuamente determinantes, ya que, si bien el espacio es socialmente construido, este también tiene cierto grado de influencia en las relaciones sociales que acoge (Ruiz-Tagle, 2016).

En los últimos años, las reflexiones sobre los poderes de la imagen espacial se han vuelto más y más favorables, investigaciones sobre lo visual en la planificación, urbanismo o arquitectura, fenómenos donde se generan vínculos entre imágenes y las realidades construidas u ocupaciones 


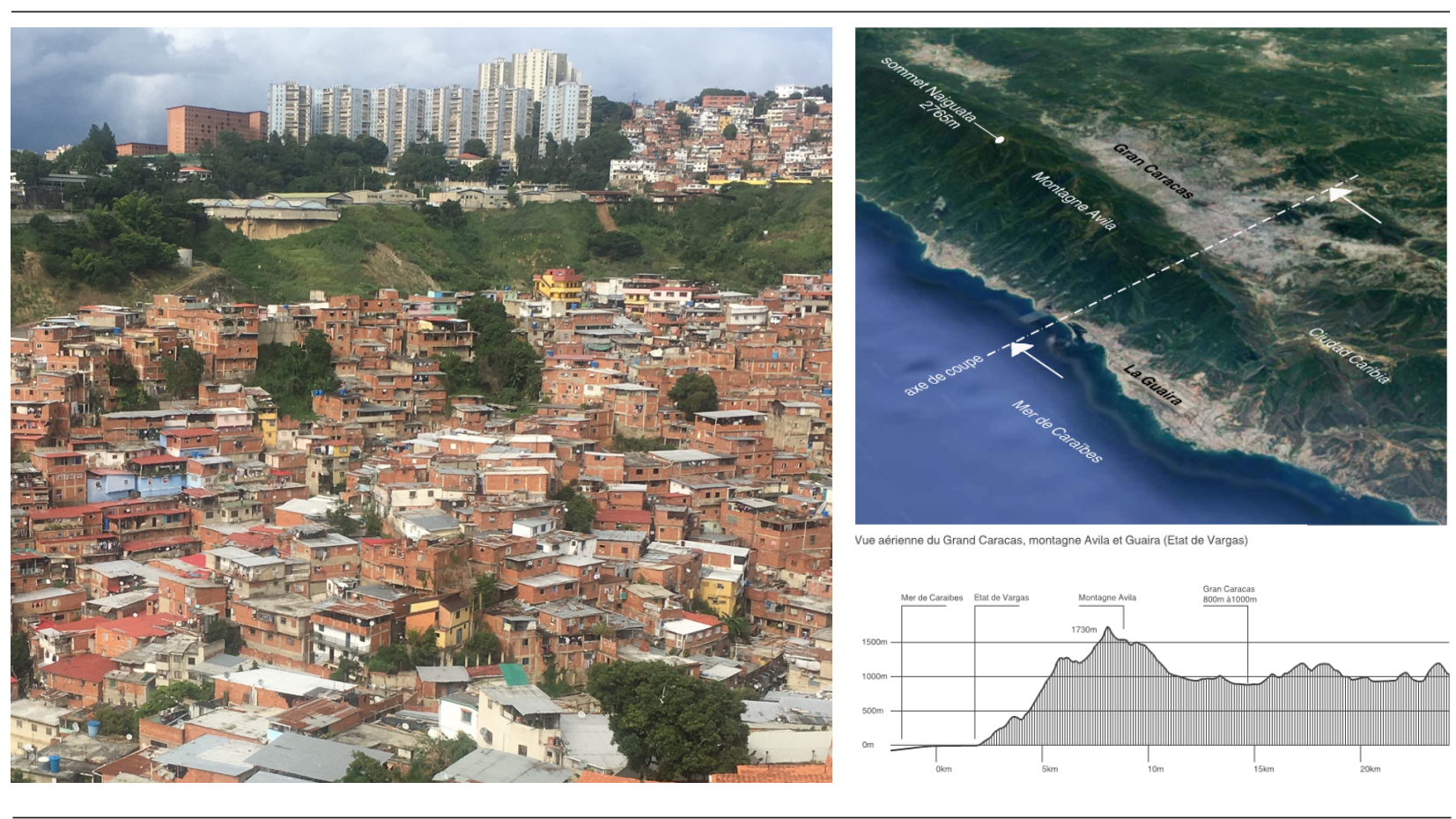

Figura 3a. Figura 3a. Barrios autoproducidos en la Gran Caracas. Fuente: elaboración propia (2019).

Figura 3b. Contexto geográfico. Corte de Ávila que muestra la Gran Caracas, Ciudad Caribia y La Guaira. Fuente: elaboración propia (2020).

espaciales. Según el Diccionario de la Geografía Espacial y de la Sociedad, el éxito y la eficacia de los documentos visuales, unido a su valor pragmático, parece deberse esencialmente a que "son instrumentos de dominación del espacio por su capacidad de reducir radicalmente su complejidad y gozan de un efecto de veracidad consustancial que permiten una perfecta representación de la espacialidad proyectada" (Lévy \& Lussault, 2003, p. 532). Por esto, podemos decir que la producción material de viviendas, así como su representación, es una operación colectiva en la cual participan: el Estado, las autoridades locales, los beneficiarios y los actores privados. Así como por la real representación política tras la producción de GMVV y que por medio de la sociología visual nos adentraremos a su análisis con el objetivo de descifrar el mensaje que conlleva esta producción.

Contexto del surgimiento de las Misiones y el origen de la GMVV: la participación como un nuevo tipo de gobernabilidad

La inestabilidad urbana y la proliferación de viviendas autoconstruidas son características del tejido urbano de Venezuela (Figura 3a), pero también de la Gran Caracas y del Estado Vargas -ahora rebautizado como La Guaira ${ }^{6}$. Estas construcciones espontáneas se desarrollaron principalmente en los años 50 , y su número se multiplicó por diez hasta los años 80 , con la explosión de las exportaciones de petróleo y el éxodo rural. Entre los recurrentes fenómenos climáticos a los que está sometida Venezuela -fuertes lluvias, inundaciones y desprendimientos, sequías, terremotos-, la "Tragedia de Vargas" de 1999 fue uno de los desastres más impactantes de los últimos treinta años, con múltiples desprendimientos en la vertiente norte montañosa (Figura 3b) del litoral central, que destruyeron decenas de miles de viviendas a su paso. En este contexto ya caótico, los episodios de lluvia de 2010 agravaron la situación, sumiendo de nuevo a los habitantes en la extrema vulnerabilidad, privados de vivienda y aún más dependientes del Estado. La geografía del país y estas influencias climáticas han reforzado la atención del Gobierno a estos territorios vulnerables donde se encuentran une mayoría de habitantes.

En el plano político-territorial, la llegada de Hugo Chávez al poder se apoya en las fuertes expectativas de la población

${ }^{6}$ La toponimia forma parte de una estrategia del actual estado venezolano que propone reescribir la historia a todos los niveles del territorio, el Estado de Vargas fue rebautizado en 2019 como Estado de La Guaira (municipio homónimo), ya que el Gobierno bolivariano quería borrar el nombre de José María Vargas (1786-1854), médico y estadista considerado antimilitarista. 
para la reducción de la pobreza, la injusticia, la desigualdad y la transformación social. Las dificultades sociales acentuadas por la emergencia de proporcionar una vivienda digna a las víctimas de estas tragedias llevaron al Gobierno Bolivariano a poner en marcha en 2002 campañas sociales y territoriales, como los instrumentos de regularización de tierras en zonas urbanas populares, los Comités de Tierras Urbanas (CTU). Además de promover la regularización y la rehabilitación de los barrios desfavorecidos, este decreto de creación de las CTU constituyó una base jurídica para dar a la población un papel político en el proceso de planificación, como es el caso de los Campamentos Pioneros (CP) (Torres et al., 2017). Cuando se crearon las Misiones en 2003, se definieron como la aplicación de políticas sociales directamente en los barrios populares y lo más cerca posible de los ciudadanos. Su principal rasgo distintivo con respecto a otros servicios públicos existentes era que estaban más cerca del terreno y al margen de las administraciones preexistentes. Las Misiones también se iniciaron en un contexto político inestable, con un intento de golpe de Estado contra Hugo Chávez ese mismo año, y en 2004, una campaña de referéndum sobre su destitución a mitad de mandato, con encuestas que predecían su derrota. Reelegido en 2006, puso en marcha la construcción de un Estado comunal, con vistas a transformar la arquitectura institucional del país: leyes, formas de participación, gestión territorial y nacional. Chávez se apoya en las organizaciones comunitarias ya creadas - las Mesas Técnicas de Agua, Energía, Salud y los Comités de Tierras Urbanas, encargados de resolver los problemas de infraestructura, saneamiento y regularización de tierras, así como las cooperativas y otras organizaciones populares autogestionadas- para instalar las nuevas instancias populares (Cariola et al., 2012), los Consejos Comunales, que, agrupados en un territorio, constituirán la "Comuna". Este proyecto, rechazado en una reforma constitucional en 2007, se plasmará en forma de leyes y decretos ley (Ley Orgánica de los Consejos Comunales en 2009 y la Ley de la Comuna en 2010) en la Asamblea Nacional. Se confiere así una autonomía al ciudadano; se ancla en el nivel local para subir a la escala regional primero y nacional después. "La Comuna [...] es solo un lugar que coordina las propuestas y las impulsa más arriba (...) En las zonas urbanas, las Comunas agrupan de 25 a 40 Consejos Comunales, y en las zonas rurales de 6 a 15" (Azzellini, 2017). En 2021, según el Ministerio de Comunas en Venezuela, habría 3.278 Comunas, 970 en construcción y 258 ciudades comunales propuestas, sin correspondencia con los municipios y parroquias preexistentes 7 . Aunque no se trata de órganos constitucionales, estos Consejos Comunales y Municipios duplican las administraciones que antes llevaban el Estado y los municipios, tal y como estipula la CRBV de 1999. En contraste, algunas cifras extraídas de los reportes de Provea (2018) y de la Cámara Venezolana de la Construcción (2017) demuestran que desde 2015 las cifras publicadas por el Gobierno sobre la construcción y el coste de las viviendas son, cuanto menos, fantasiosas. Destacan la falta de acceso a la información, la incoherencia de los precios (una media de 83.000 dólares por vivienda, un valor colosal según la $\mathrm{CVC}$, que estima el valor real de la construcción en solo 8.000 dólares/vivienda) y las contradicciones en las cifras de ejecución, es decir, 25.000 viviendas/año construidas frente a 300.000 según los anuncios del Gobierno.

En el análisis de nuestro terreno observamos que esta nueva representación de la organización funcional y territorial, los ciudadanos se enfrentan efectivamente a dos estructuras paralelas sin poder distinguir siempre quién hace qué. Si bien los Consejos Comunales tienen la tarea de cogestionar las políticas sociales y urbanas con el Gobierno en los barrios autoconstruidos y en las nuevas operaciones de la GMVV, también se encuentran en la confluencia de un triple movimiento: desconcentración del Estado, desconexión de las políticas públicas de un antiguo poder central $\mathrm{y}$, sobre todo, politización de los barrios obreros. Estos Consejos Comunales y Comunas representan no solo el poder político más cercano al ciudadano, sino también un poder directamente vinculado al ejecutivo nacional y al presidente de la República.

¿Podríamos asociar estas acciones y el lugar dado a la participación ciudadana como un tipo de gobernabilidad? $\mathrm{Si}$ entendemos la gobernabilidad como un estado de equilibrio dinámico entre demandas sociales y capacidad de respuesta gubernamental, así como la eficacia y legitimidad que se combinan positivamente garantizando la estabilidad del sistema político (Camou, 2001).

Lo que podría entenderse como que "asistimos a la continua e incesante postergación de los límites de la gobernabilidad" (Niño Araque, 2005). Premonitoriamente, el arquitecto venezolano William Niño Araque predijo que el siglo XXI marcaría la ruptura entre la evolución de una ciudad tradicional y el fracaso de la proyección de la ciudad como parámetro de un proyecto de cohesión social.

\footnotetext{
${ }^{7}$ Según la CRBV, Venezuela es un Estado federal dividido en 23 Estados (más la capital), 335 municipios autónomos y 1146 parroquias. La "ciudad" o metrópolis está bajo la égida de una alcaldía central, el "municipio" es administrado por una alcaldía de sector y la "parroquia" es el equivalente al barrio.
} 


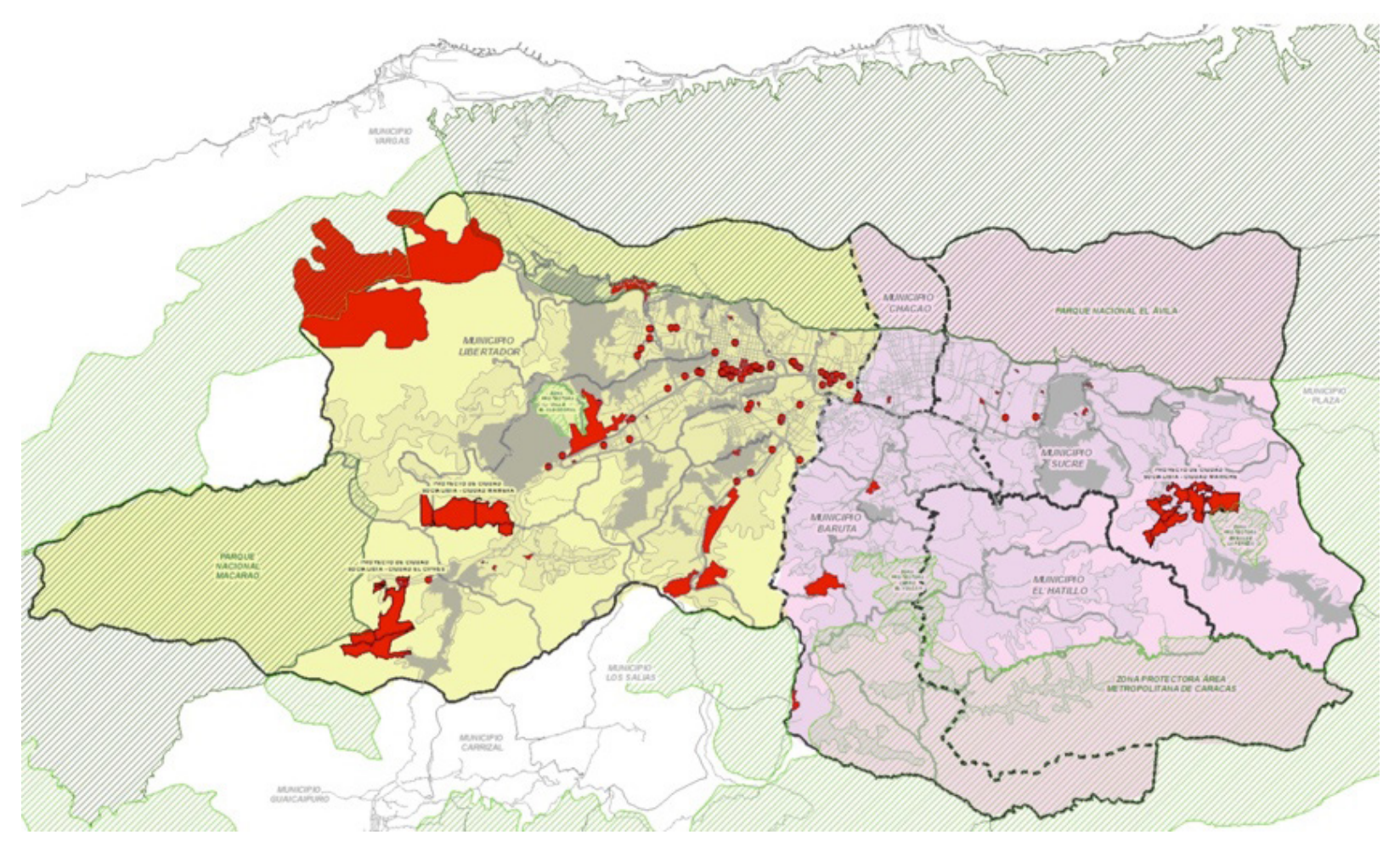

Figura 4. Ubicación de operaciones GMVV en color rojo, a la izquierda en amarillo el Municipio Libertador y a la derecha cuatro municipios donde es menos presente la producción de la GMVV. Fuente: IMUTC (2017).

El deseo de satisfacer las necesidades de vivienda a muy corto plazo, sin una verdadera planificación urbana, ha provocado cambios irreversibles en el paisaje y el tejido urbano, enmascarando los procesos de urbanización de siglos anteriores.

Para clarificar esta idea podemos mencionar el caso de Caracas, capital de la República Bolivariana de Venezuela, constituye hoy una unidad político-territorial de escala metropolitana, donde se produce una fragmentación institucional, política y administrativa que da origen a desequilibrios entre los gobiernos que lo conforman y una crisis de coordinación, que, hasta la fecha, no ha sido posible solucionar dentro del marco legal vigente, para generar innumerables conflictos e impedir el desarrollo potencial que hoy la ciudad demanda según los expertos del Instituto de Urbanismo Metropolitano de Caracas. El ámbito geográfico de la Alcaldía Metropolitana de Caracas comprende desde el año 2000 el municipio Libertador del Distrito Capital y los municipios Baruta, Chacao, Hatillo y Sucre del Estado Miranda. El primero, partidario del Gobierno, es el único que actualmente recibe recursos directos del Ejecutivo nacional y por ende es allí donde existe la proliferación de los proyectos de construcción de viviendas (Figura 4) que a la vez presentan bien el panorama de las imágenes políticas a granel y que mostraremos más adelante. Con respecto a la participación y la figura del poder popular en la gestión del espacio podemos decir que según la historiadora Margarita López Maya (2012), las primeras innovaciones participativas, creadas de acuerdo con la CRBV de 1999, fueron conceptualizadas como organizaciones civiles, con una personalidad jurídica regida por el Código Civil. Se pensaba que estimulaban una dinámica participativa desde abajo, que se suponía que fomentaba la autonomía y la responsabilidad de los interesados, pero esto ya no es así con los Consejos Comunales y las Comunas. De hecho, según el sociólogo Edgardo Lander (2007), estos últimos parecen ser sectarios, como espacios políticos exclusivos de los partidarios del Gobierno, que cuestionan el futuro de la democracia en el país. Como señala P. Vásquez, esta Ley de Consejos Comunales sentó las bases de un nuevo Estado que resultó ser una enorme máquina clientelar. La democracia participativa, que tantas esperanzas había suscitado entre los intelectuales progresistas de todo el mundo, se quedó en un deseo (Vásquez, 2014). 


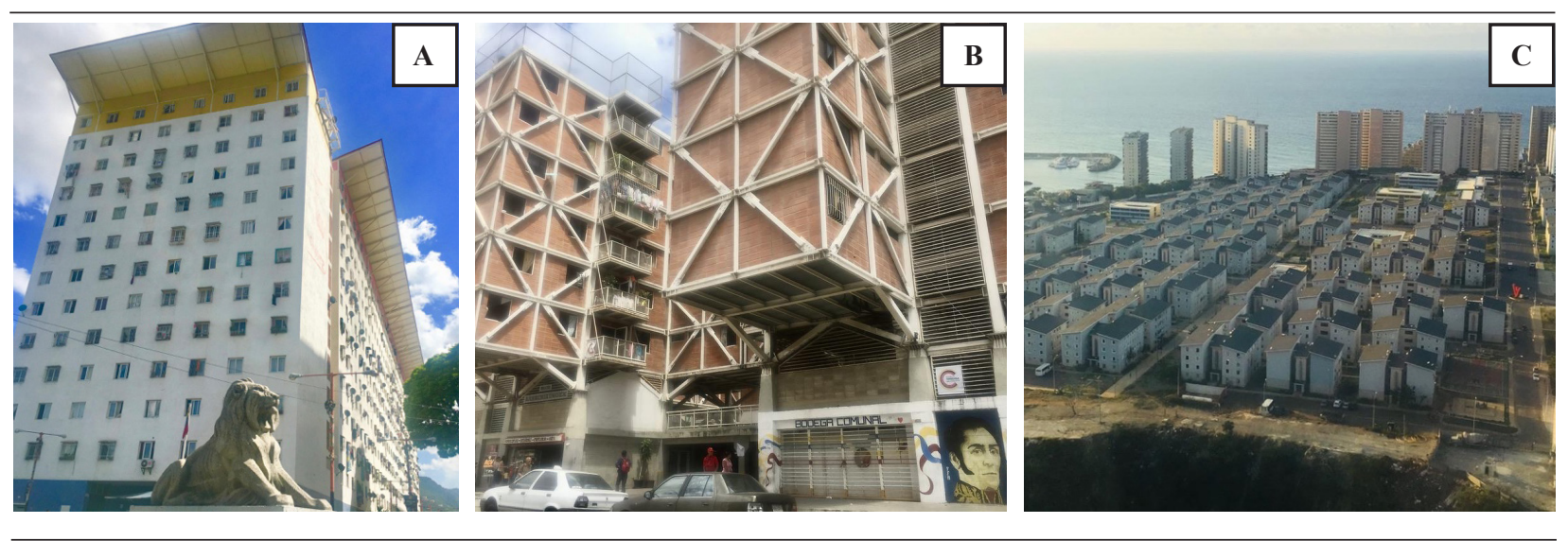

Figura 5a. GMVV, Puente los Leones, La Paz, Caracas. Distrito Capital.

Figura 5b. GMVV Santa Rosa, architecte Fruto Vivas, Caracas.

Figura 5c. GMVV La ciudad socialista Hugo Chávez. Fuente: YWW (2017-2019).

El modelo de construcción de viviendas sociales de la GMVV: tipología y morfología urbana

La morfología urbana cuestiona la interacción entre las formas arquitectónicas y una sociedad (o un conjunto de actores) en función de las condiciones históricas de construcción y expansión de la ciudad. Es el resultado de una evolución más o menos espontánea o planificada por los poderes públicos. Según Pierre Merlin (1989), se trata de "realizar una lectura técnica de la ciudad en función de la evolución de la forma urbana en relación con los cambios sociales, económicos, demográficos [...] y políticos" (p. 292). El trabajo de campo permitió definir una tipología edilicia y una morfología urbana de las operaciones de la GMVV según tres tipos de producción: proyectos de planificación no urbana de tipo "genérico", con el Estado como principal ejecutor, y estandarización en la producción de viviendas sociales (Figura 5a); ciudades compactas que incluyen en el mismo edificio equipamientos (espacios socioproductivos, escuela, instalaciones deportivas), proyectados con arquitecto (Figura 5b); ciudades socialistas, que forman parte de un desarrollo estratégico mediante acuerdos internacionales, como la Ciudad Hugo Chávez de La Guaira con Turquía (Figura 5c).

Para lograr los objetivos de construcción masiva y rápida de viviendas, el Gobierno definió mecanismos que definen varios tipos de "zonas" territoriales según criterios geográficos y de emergencia en términos de ocupación, riesgo y peligro. AREHA: Área de Emergencia Habitacional (Figura 6a), ZORI: Zonas de Riesgo, ZOPO: Zonas de Peligro Potencial, ZOPI: Zonas de Peligro Inminente y las AVIVIR: Áreas Vitales de Viviendas y de Residencias.
Para continuar los objetivos de construcción, el Estado recurrió a procedimientos operativos bastante atípicos, ninguna convocatoria pública de proyectos y mediante la adjudicación directa de contratos. Para desarrollar teóricamente su capacidad técnica y operativa, el Gobierno recurrió a sus principales aliados internacionales: China, Rusia, Bielorrusia, Irán, Cuba y Turquía. Si hacemos un breve recordatorio sobre la historia o el sistema de construcción más convencional para las viviendas sociales en Venezuela, encontramos que estas se caracterizan por una estructura de columnas y vigas en hormigón y generalmente las paredes son de ladrillos rojos huecos o a veces de bloques de hormigón con una altura media de cuatro pisos. En contraste, la GMVV suele basarse en modelos de construcción de estructuras metálicas estandarizadas y prefabricadas, con la producción de torres que superan las 10 plantas. Lo que requiere de otros elementos constructivos más sofisticados, como el uso de ascensores, que requieren una tecnología y una gestión que hacen más complejo el modo de vivir aunado al fuerte contexto de crisis del país. Al mismo tiempo se observan que por la escogencia de la prefabricación importada, el uso de ventanas minúsculas cuya disposición repetitiva en la fachada refleja una escasa reflexión arquitectónica de manera generalizada. Elementos sin uniformidad, criterio, ni identidad, sin diálogo con el contexto urbano que podemos asociar a una arquitectura bastante precaria. Por último, la presencia e incluso la huella de los constructores internacionales influyen en la apropiación de este nuevo hábitat por parte de los habitantes. Algunos asocian sus nuevos barrios GMVV con las nacionalidades de los países aliados constructores, para crear nuevas identidades. Los habitantes explican el proyecto diciendo "el barrio de 


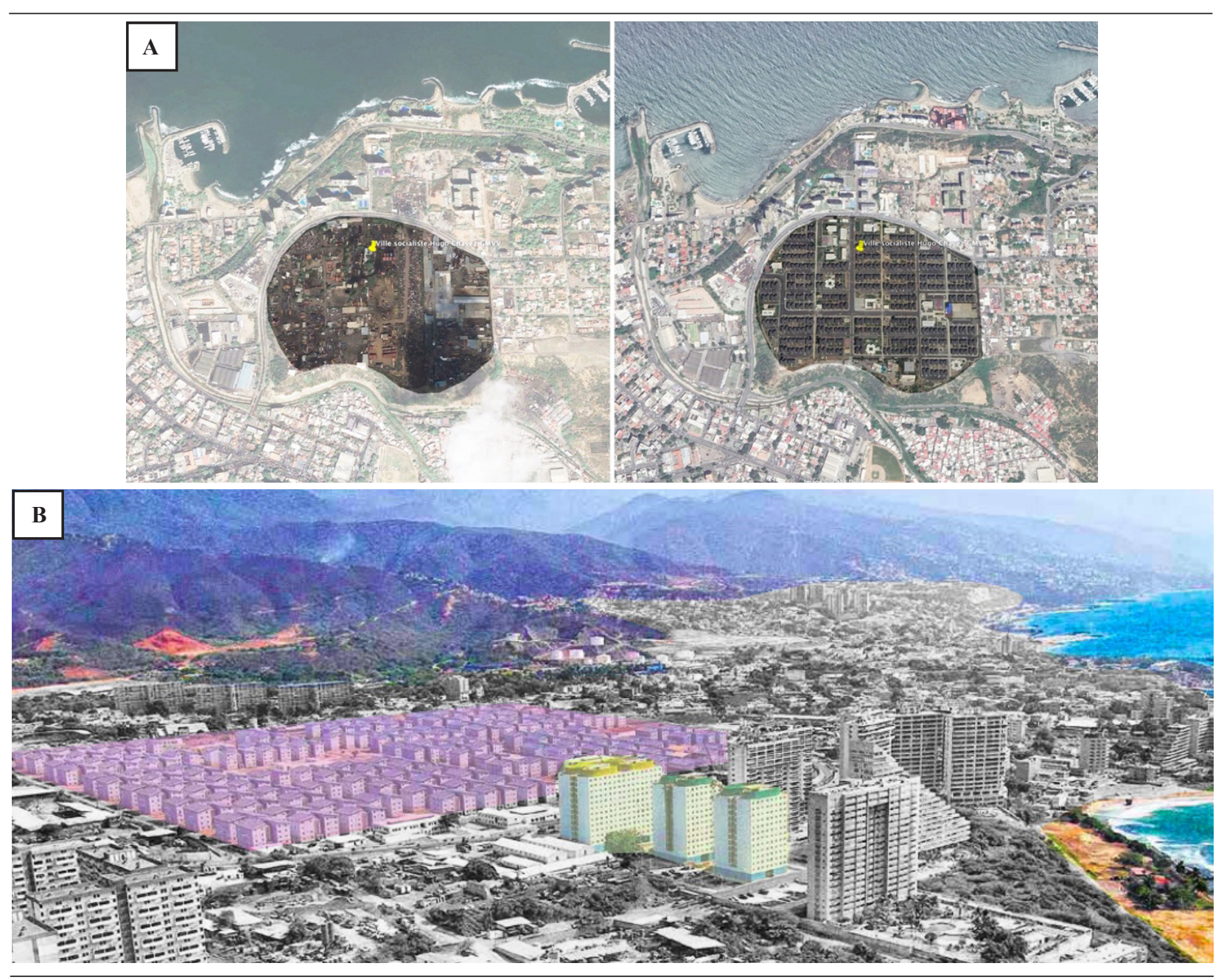

Figura 6a. Arriba: izquierda en 2010 y derecha en 2018. Fuente: Google Maps (2010-2018).

Figura 6b. La ciudad socialista Hugo Chávez producida por acuerdos internacionales con Turquía (en morado) y a la derecha (en amarillo) 384 viviendas construidas por la OPPPE. Estado La Guaira. Coordenadas geográficas del Estado La Guaira 10³6'38"N 66²4'06"W. Fuente: OPPPeración Ciudad. (Intervención de la autora). Fuente: Correo del Orinoco (2013).

los chinos, los edificios rusos, el sector bielorruso o el proyecto cubano" (comunicación personal, s/f).

Otro ejemplo es que antes de la GMVV, en el año 2007, se construyeron o crearon las casas individuales llamadas Petrocasas con piezas modulares y paneles de cloruro de polivinilo (PVC) y otros derivados del petróleo, por ello su nombre. Su montaje es bastante rápido y sencillo. El principio constructivo de la Petrocasa ha sido recuperado por la GMVV en forma de viviendas en altura de diez pisos y más (Figuras 7a y 7b). Algunos habitantes afirman que las paredes de PVC no son paredes de verdad, ya que no les permiten colgar cuadros o, para los más irónicos, que viven en una nevera. El material considerado como el más noble o de buena calidad en la percepción de los habitantes sigue siendo el bloque de arcilla rojo (Figura 7c) o gris para construir los muros y el concreto para las columnas, aunque puede ser bastante aceptada la estructura metálica, pero en todo caso, que sea «siempre visible» (Wilson, 2020).

\section{Sobre la mercadotecnia política y territorial: identificación y propiedad}

La mercadotecnia política puede entenderse como:

un sistema de actividades para planificar, promover y distribuir un producto político ya sea una organización, un programa, un candidato o idea, para satisfacer las necesidades de ciertos grupos de ciudadanos o de la población en su conjunto, de acuerdo con un objetivo político. (Vásquez Romero 2014, p.4) 


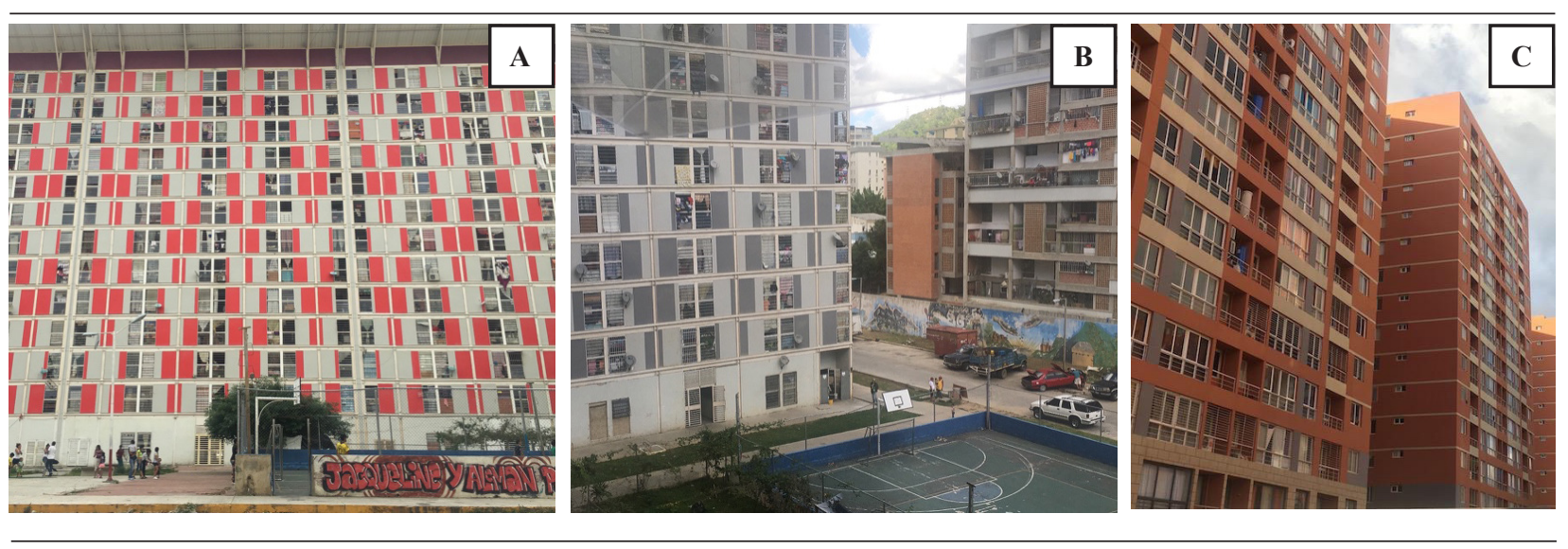

Figura 7a y 7b. GMVV, paneles en PVC, Montalbán, Caracas.

Figura 7c. Ciudad Tiuna, Caracas (acuerdo con China, Rusia y Bielorrusia). Fuente: YWW (2017-2019).

Esta noción puede vincularse al concepto de propaganda, entendiéndole como el conjunto de técnicas de persuasión, implementado una idea, una opinión, una ideología o una doctrina a través de todos los medios posibles, con el fin de estimular la adopción de un comportamiento predeterminado dentro de un público determinado (Valdez Zepeda \& Huerta Franco, 2020). Estas técnicas se ejercen sobre una población para influenciarla o incluso adoctrinarla.

De una forma neutra, la propaganda se define como una forma intencional y sistemática de persuasión, con el objetivo de influir en las emociones, actitudes, opiniones y acciones de los grupos destinatarios para alcanzar objetivos ideológicos, políticos o empresariales, a través de la transmisión controlada de mensajes de información parcial (que puede o no ser real) a través de los canales directos de masa y medios. (Nelson, 1966, p. 232)

El propósito de esta descripción es profundizar sobre las imágenes vectoriales ${ }^{8}$ de la mirada y la firma del presidente Hugo Chávez quien falleció en 2013 y cuya reproducción ha sido fulgurante como mercadotecnia política y territorial en Venezuela. La estrategia visual los "Ojos de Chávez" nació durante la campaña electoral en 2012, fuertemente inspirada del Pop Art y de la idea de consumación masiva propuesta por Andy Warhol en los años 70 (Figura 8) por iniciativa de José Miguel España, miembro del grupo político del Comando Carabobo.

La segunda representación más emblemática fue la réplica gigante de la firma de Chávez conocida como 'rabo de cochino' (cola de cerdo) por la curva de su trazo. Durante esta campaña hubo un despliegue masivo de objetos figurativos de Chávez que involucró a ciudadanos de todas las edades. Reproducido en camisetas, banderas, pancartas y otros accesorios de uso personal y en nuestro caso nos interesaremos en mostrar esta representación en el espacio urbano, vallas, muros y fachadas de edificios públicos (Figura 9), en edificios existentes en barrios precarios en todas las operaciones GMVV e incluso al interior de algunos apartamentos.

En 2014, el Centro Nacional de Historia publicó un documento titulado "Rostros y rastros de un líder. Hugo Chávez: memoria de un pueblo" (Barbarito et al., 2014). Entre los aspectos analizados en las campañas políticas estaba el fuerte impacto visual de los "Ojos de Chávez". Su poder semiótico en términos de importancia ideológica y emocional ha dado lugar a varias interpretaciones. Según este informe, los "Ojos de Chávez" representan una mirada vigilante y protectora: "Te veo" parece representar también el carácter visionario del político. Desde hace ya muchos años se ha creado un culto y adoración en torno a la figura de Chávez y la apropiación de la firma como identificación

\footnotetext{
${ }^{8} \mathrm{La}$ imagen vectorial se entiende como un tipo de trazo de formas geométricas simples, lineal, clara, monocromática, fácilmente reproducible y cuya característica más importante es que nunca se podrá deformar, lo equivalente a decir en términos informáticos es que es "im-pixelable". Otra particularidad para retener en el concepto del vector es la fácil capacidad de reproducción que al mismo tiempo favorece la fijación en el cerebro o afirmarlo como un símbolo. Es un recurso altamente utilizado para reforzar una estrategia visual en las masas. En las instituciones corporativas públicas o privadas estos son recursos frecuentemente utilizados para ganar la confianza del grupo de la organización o sus seguidores. Una de las ideas en la creación de este tipo de imagen es el rápido reconocimiento por parte de los observadores, lo cual ayuda a la fácil identificación de una parte y de lo que ello representa. La imagen se convierte en ese momento en un objeto y el éxito se logra cuando el ser cautivado se apropia del icono o del símbolo hasta sentirse identificado.
} 


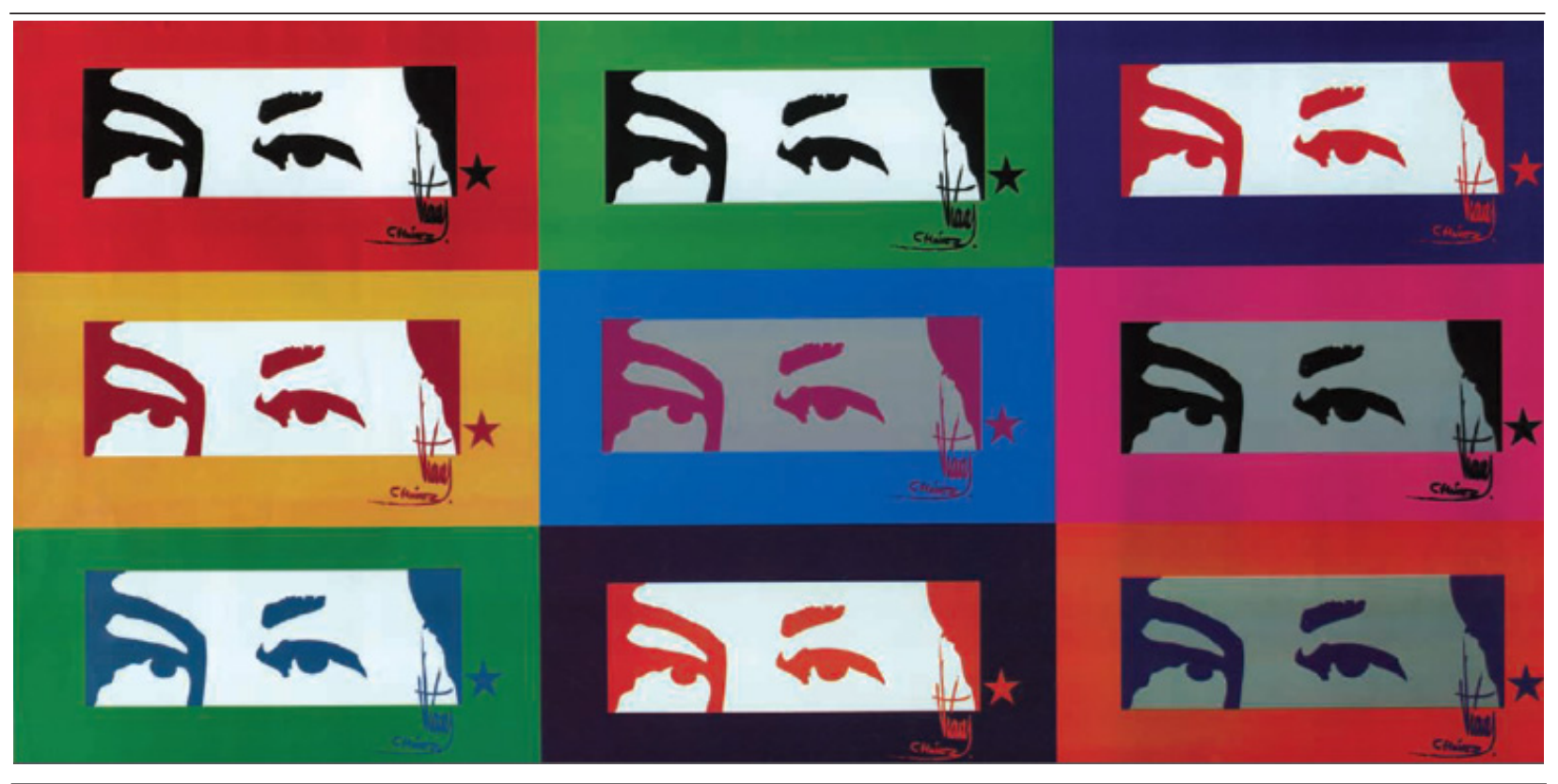

Figura 8. Los "Ojos de Chávez", campaña presidencial 2012. Fuente: Comando Carabobo.

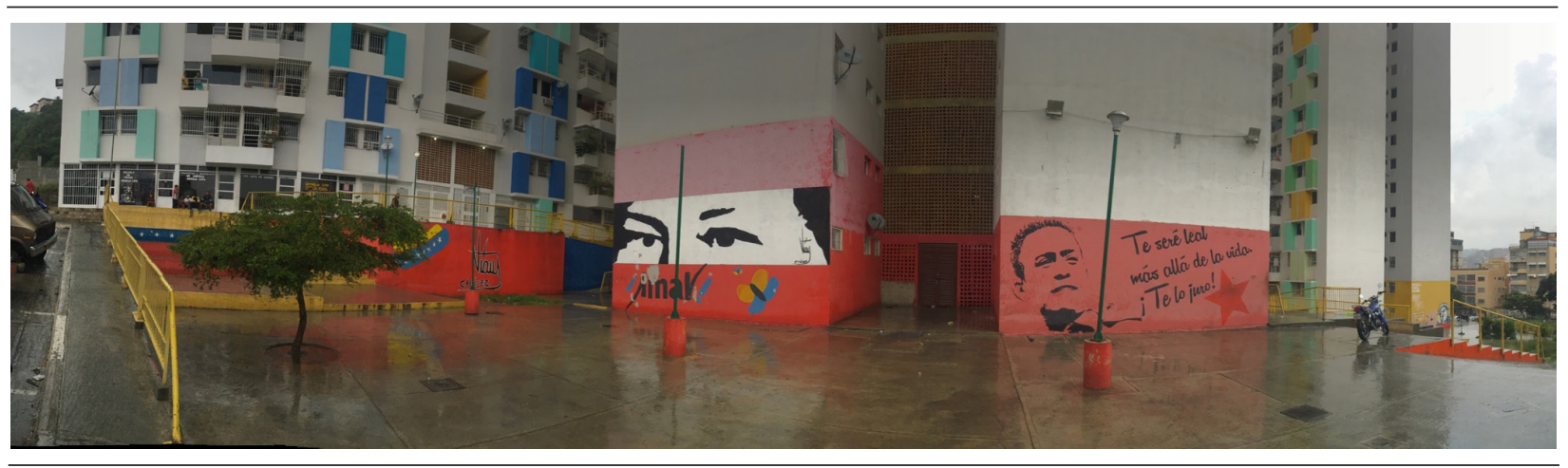

Figura 9. Operación GMVV en la Avenida Victoria. Coordenadas geográficas $10^{\circ} 29^{\prime} 12^{\prime \prime} \mathrm{N} 66^{\circ} 54^{\prime} 17^{\prime \prime W}$. Fuente: elaboración propia (2019).

de una sociedad a través de estas imágenes vectoriales. Los "Ojos de Chávez" simbolizan esa mirada agradable, cercana, inclusiva y la "firma" simboliza la entrega de una propiedad a la otra, en este caso la otra representa al pueblo. Algunos reconocen las viviendas de la GMVV como "las casas de Chávez", ya que fue él quien promovió las casas como política pública y las personas lo reciben como un regalo de su parte. Aunque la pertenencia siga siendo del Estado o supervisada y vigilada a través de esta mirada o simbología del propietario.

\section{¿Una propiedad colectiva es posible?}

Esta visión social cruzada con el proyecto de una vivienda ideal también plantea otras interrogantes, en cuanto se aborda el tema desde el ángulo de la propiedad, del bien individual. Comenzando por las modalidades de acceso a la vivienda de GMVV donde los solicitantes tienen dos posibilidades: acceso "gratuito" a víctimas de una situación de emergencia y/o sin techo, y la obtención de un préstamo a la "clase media". Según la jurista Laura Louza Scognamiglio en Duque et al (2016), "ahora existe un nuevo tipo de propiedad denominada propiedad familiar y plurifamiliar, que se encuentra entre lo público y lo privado". Este tipo de propiedad se fundamenta en el derecho de uso, goce, usufructo de una propiedad por parte de los habitantes, pero se diferencia en la infraestructura - los muros- que quedan como propiedad del Estado y la tierra, que se entrega al Consejo comunal o al Comité de Gestión Familiar durante 100 años mientras exista igualmente la Comuna. 
Sin embargo, los beneficiarios de la vivienda de GMVV conocen culturalmente el valor del título individual, e imaginar una solución colectiva, una especie de posesión conjunta con el Estado, no siempre corresponde con sus deseos. Durante las encuestas por cuestionario realizada a los 24 habitantes de la operación GMVV, algunos residentes dicen que se sienten "a la espera de" o "a la disposición de" las decisiones estatales sobre la asignación de viviendas o la emisión de propiedad común. Otros, titulares o no del título de propiedad, evocan el hecho de que las viviendas les pertenecen desde un punto de vista legal, pero también dicen que no se atreven a modificarlas o apropiarse de ellas, porque pueden ser trasladadas en cualquier momento. La inclusión de estos nuevos modelos de propiedad asignados a edificios convencionales con modelos de apartamentos individuales igualmente, en los que la forma de vida todavía está restringida a la misma configuración clásica de vivienda individual, ha llevado a los residentes a esperar títulos de propiedad individuales. A lo que nos respondió en la entrevista realizada al arquitecto Fruto Vivas:

Hay que revolucionar el diseño de los apartamentos o viviendas, ¿qué sentido tiene multiplicar las lavadoras y secadoras individuales, un juego en cada unidad, como viene haciendo la pequeña burguesía desde hace años en todos los países capitalistas desarrollados, cuando pueden integrarse perfectamente en locales comunes con gran eficacia?... No hacerlo sería un grave error político. (comunicación personal, s/f)

De las conferencias dadas en el Foro GMVV (2016) por los arquitectos Juan Carlos Rodríguez en oposición a Juan Pedro Posani ${ }^{9}$ considera que la GMVV no puede seguir pensando en el objeto de vivienda como el objeto "fetichista", "mágico", "religioso" que generará la transformación de la sociedad. No es el objeto "colectivizado" o "común", sino su proceso de producción y gestión. En el campo, parece que el hecho de seguir diseñando viviendas sociales de manera individual en su uso no hace comprensible la propiedad colectiva como propone el programa.

Si bien es cierto que las teorías de Harvey (2011) y Lefebvre (2013) valoran el uso de la tierra, el poder del usuario sobre ella y, sobre todo, desmitifican el dominio del Estado como primer y único gestor de esta propiedad, las diversas experiencias encontradas en el mundo y en la historia muestran nuevos modelos relacionales que se derivan de esta apropiación territorial. Las referencias más recientes apuntan a la relación causaefecto entre la convivencia y las nuevas prácticas de apropiación que, en nuestra problemática principal, parece tener un impacto en la producción del espacio. Igualmente, en determinados procesos de creación de políticas públicas y determinados programas de vivienda social son utilizados como objeto de propaganda, en este caso de la GMVV, la misma va cargada además de una simbología que incide en el hábitat de los beneficiarios. No es solamente el edificio o la vivienda como objeto de propaganda es también la iconografía transmitida como código común del actual proceso político venezolano. Además de los instrumentos políticos territoriales de control de la población que forman parte de un proselitismo ${ }^{10} \mathrm{y}$ control del Estado hacia los habitantes.

Los resultados de las entrevistas realizadas a los ocupantes revelaron el "gran sueño social", el de poseer un título de propiedad, perfectamente identificado y reivindicado para algunos habitantes. Pagar está asociado a un tipo de reconocimiento de valor en el que el Estado los ubica, donde algunos pagan un crédito y otros piensan que su lealtad al Estado se equipará a una forma de pago. Otra constatación es que, en esta política de vivienda social, el Estado elige quién puede beneficiarse de ella o no, creando así una nueva forma de privilegio y en consecuencia los hombres se convierten en seres de intercambio (Wilson, 2020). Esta reflexión permite establecer el vínculo con el célebre trabajo del antropólogo francés Marcel Mauss, Ensayo sobre el don. Forma y razón del intercambio en sociedades arcaicas (1923), que explica cómo la noción de "don" es transformada en "obligación". Concretamente, en los resultados de mis entrevistas, algunos se refieren a las viviendas de la GMVV como "las casas de Chávez", ya que fue él quien promovió la construcción y los habitantes lo reciben como un regalo de su parte.

\footnotetext{
${ }^{9}$ Más información, ver enlace: https://musarqve.blogspot.com/search?q=foro+gmvv +

https://juanpedroposani.wordpress.com/2020/01/22/notables-aciertos-y-graves-errores-de-la-gmvv-1-parte/

${ }^{10} \mathrm{El}$ proselitismo son todos los medios dedicados a convencer a los nuevos adeptos de una causa política, como una elección, una rebelión o cualquier otro movimiento político. En las campañas electorales, este término se utiliza para describir los intentos de inducir un cambio de preferencia política en favor de otra. Es común que se utilice para criticar un comportamiento considerado negativo para la convivencia política en el sentido de que se supone que los que practican violan las reglas de la justicia y fuerzan el cambio de opinión de los demás a través del engaño o de una licitación, una campaña política demagógica.
} 

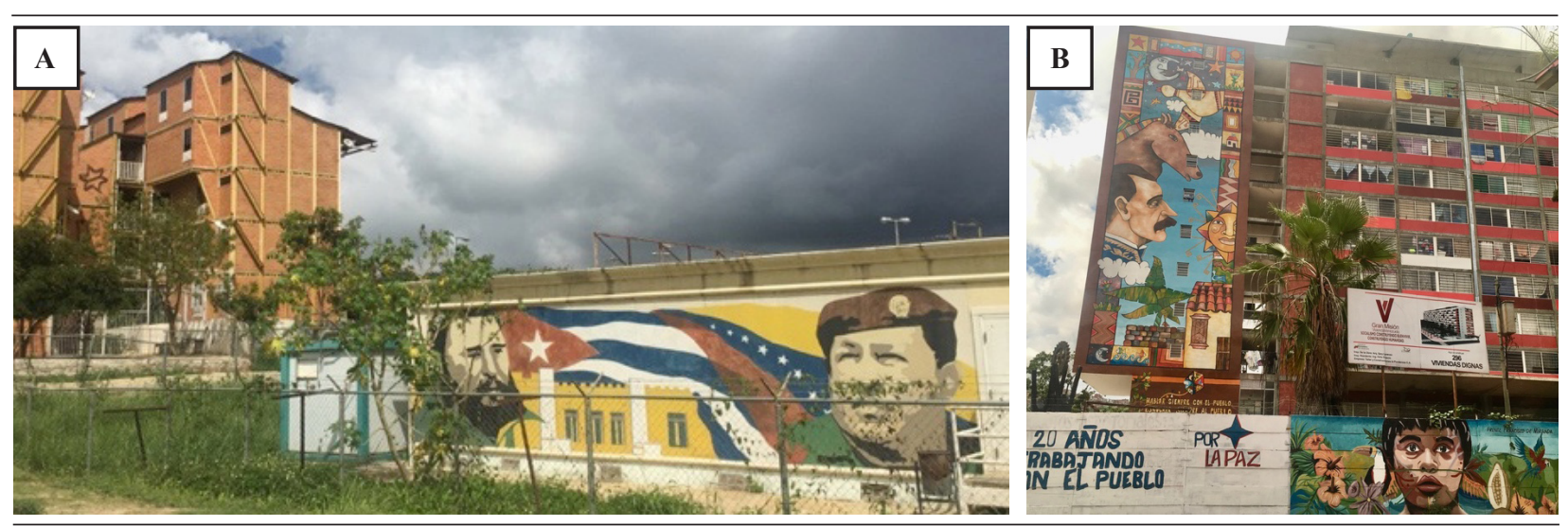

Figura 10a. Mural con la figura de Fidel Castro y Hugo Chávez en Ciudad Caribia. Figura 10b. GMVV Avenida Bolívar. Fuente: elaboración propia (2017-2019).

\section{Arte urbano y muralismo político de la Revolución Bolivariana}

Si bien existe una influencia histórica del muralismo latinoamericano en el país, lo que nos llama la atención es la efervescencia actual de estas representaciones como medio de comunicación común a todos los actores de la ciudad. En sociología, existen estudios sobre el proceso de creación de estos dispositivos como instrumentos de comunicación o como la ocupación de "terrenos de disputa" según Molina Loyola (2020). La mayoría cuestiona a los diseñadores, pero pocos se ocupan sobre la percepción de los habitantes. En el caso de Venezuela, esta técnica de muralismo se cataloga inmediatamente como "guerra comunicativa" o "arte callejero político" con la producción de "murales anticapitalistas" de la década de 1960. Como señala Fabrice Andréani (2013), "nosotros encontramos aún hoy, en diversas configuraciones territoriales, urbanas y rurales, populares, como burguesas (...) dos inscripciones sintomáticas de la participación popular en esta empresa heterogénea: Cuando los medios de comunicación digan la verdad, los muros callarán". "Paredes blancas, cerebros vacíos". De igual manera, el investigador Tarragoni (2016) explica que este arte callejero forma parte de los barrios de Caracas incluso antes de que Chávez llegara al poder y poniendo en imágenes el imaginario guerrillero radical: Tupac Amaru, Che Guevara, Fidel Castro (Figura 10a), Pancho Villa, Emiliano Zapata, Augusto Sandino, luego Lenin, Mao Tse-Toung, Trotsky, Hô Chi Minh. Una "América Latina en lucha" o que muestra sus aliados representada en las paredes de la ciudad o en la parte baja de los edificios (Figura 10b).

En nuestro estudio constatamos la existencia de una cultura de imagen o espacio de indicar un acuerdo o desacuerdo político a la representación del Estado, este último se ha ocupado de incluirla de manera masiva en el espacio público y hoy día forma parte del imaginario de los ciudadanos del país. Observamos un tipo de street art que no se diferencia demasiado del muralismo institucional y que son incluidos en los espacios comunes y en el espacio privado de vivienda social que realiza el Estado. La figura de Chávez con Maduro (Figura 11) convive con un mural de protesta realizado por las brigadas muralistas (Propaganda Bolivariana Comando Creativo y Frente Francisco de Miranda) en colaboración con los habitantes, que crea un ambiente particular "izquierdista". El trabajo de las dos brigadas se caracteriza por una pintura muy colorida en las paredes, que representa a diferentes personajes a gran escala, en una estética armoniosa, que valora sobre todo los rostros de las personalidades e ideales a los que se adhieren políticamente estas brigadas.

El uso de murales con diversas técnicas (cerámica, mosaicos, vidrio reciclado, pintura) en el país es visible en todo el paisaje urbano. Una especie de colorida exposición política ocupa todas las paredes vacías de la ciudad. En muchos casos, estos frescos son realizados por el propio Estado, ya que están firmados con logotipos ministeriales. Sin embargo, lo que nos llamó la atención en nuestra última visita realizada en 2019 fue que Nicolás Maduro ocupa solo un lugar secundario en el imaginario de la gráfica urbana (Figura 11). La figura de Hugo Chávez siempre aparece en primer plano y la silueta de Maduro siempre está detrás, debajo o en el fondo.

Otro ejemplo de cómo esta representación en el espacio público produce un intercambio comunicativo entre los distintos actores de la ciudad -el Estado, los muralistas y los habitantes-, podemos observarlo en la imagen de la izquierda (Figura 12a), donde la pintura está parcialmente borrada en el pecho de Chávez, lo que puede interpretarse como una forma de idolatría por parte de los transeúntes. 


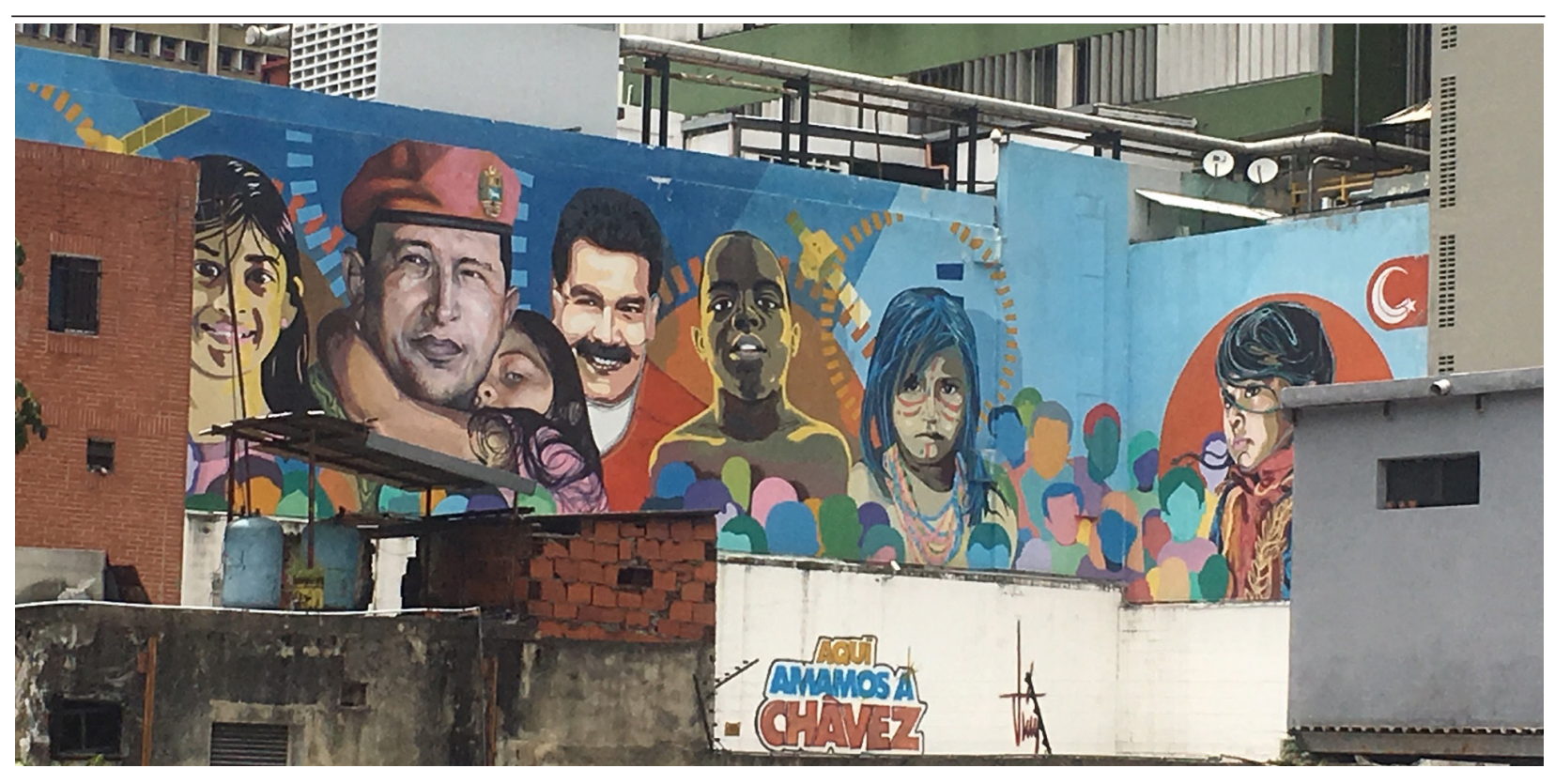

Figura 11. Imagen tomada en el centro de Caracas. Mural realizado por la Brigada Muralista Propaganda Bolivariana Comando Creativo. Fuente: elaboración propia (2019).
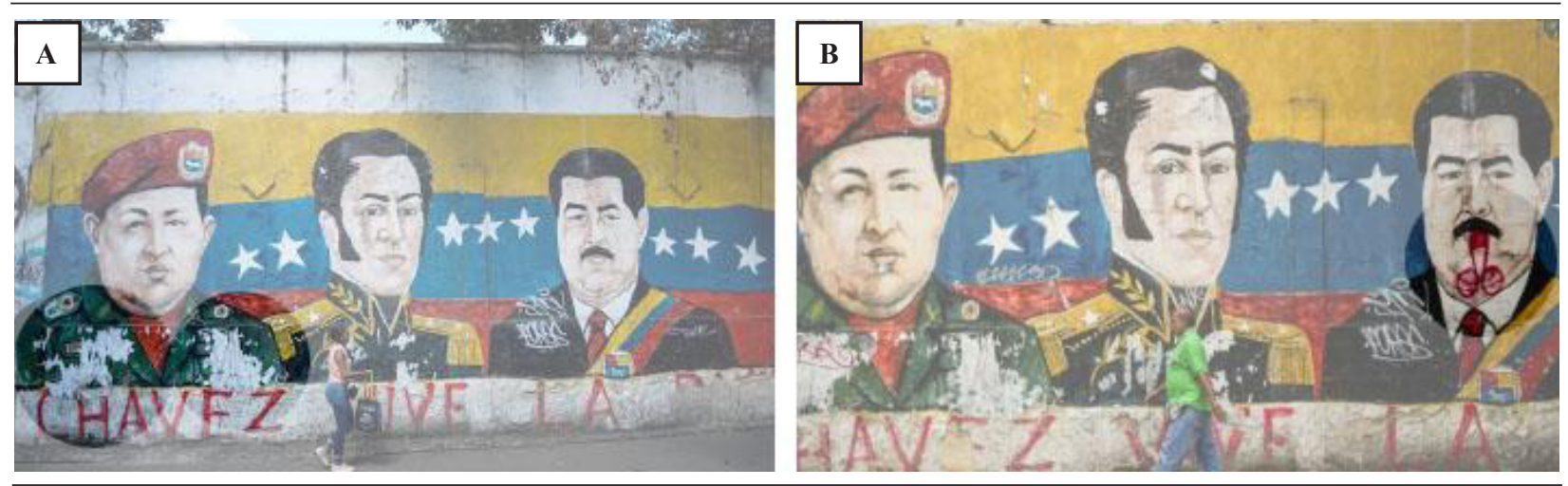

Figura 12a y 12b. En este mural ubicado igualmente en Caracas se observan las figuras políticas contemporáneas, Chávez a la izquierda y Maduro a la derecha, están emparejadas con la figura histórica de Simón Bolívar en el centro. Debajo de estas tres caras, un mensaje: "Chávez vive, la revolución sigue". Fuente: A la izquierda Federico Parra (The Guardian, 2015); derecha AFP (2017).

Esta falta de pintura parece reflejar la vehemencia de los transeúntes que tocan la imagen de Chávez y no la de los demás personajes. Otros registran su desacuerdo dibujando un pene en la cara de Maduro (Figura 12b). Por mucho que las figuras de Chávez y Maduro provoquen reacciones, la figura histórica de Bolívar permanece intacta. Esto puede verse como una falta de identificación o una forma de respeto por esta figura histórica. También se observa un rechazo más marcado a la imagen de Nicolás Maduro en contraste con la de Hugo Chávez. Una conclusión podría ser que la campaña de comunicación llevada a cabo bajo el mandato de Chávez tuvo y sigue teniendo un impacto significativo en la población.
Para culminar esta parte, otro de los ejemplos más emblemáticos que podemos mencionar es el monumento Las escaleras de El Calvario, etiquetado patrimonio de la nación en 1983. En este monumento, adeptos al Gobierno pintaron los "Ojos de Chávez" en gran formato sobre los peldaños de la escalera aprovechando el carácter visible del espacio y su ubicación en el centro de la ciudad. En ese instante, la arquitecta venezolana y la presidente de la Fundación de la Memoria Urbana, Hannia Gómez declaró en una entrevista el 2016 en el diario El Nacional: "Este es un nuevo ataque contra el patrimonio de la nación y un abuso de poder. Las escaleras de El Calvario no son una valla o panel publicitario para hacer de la 


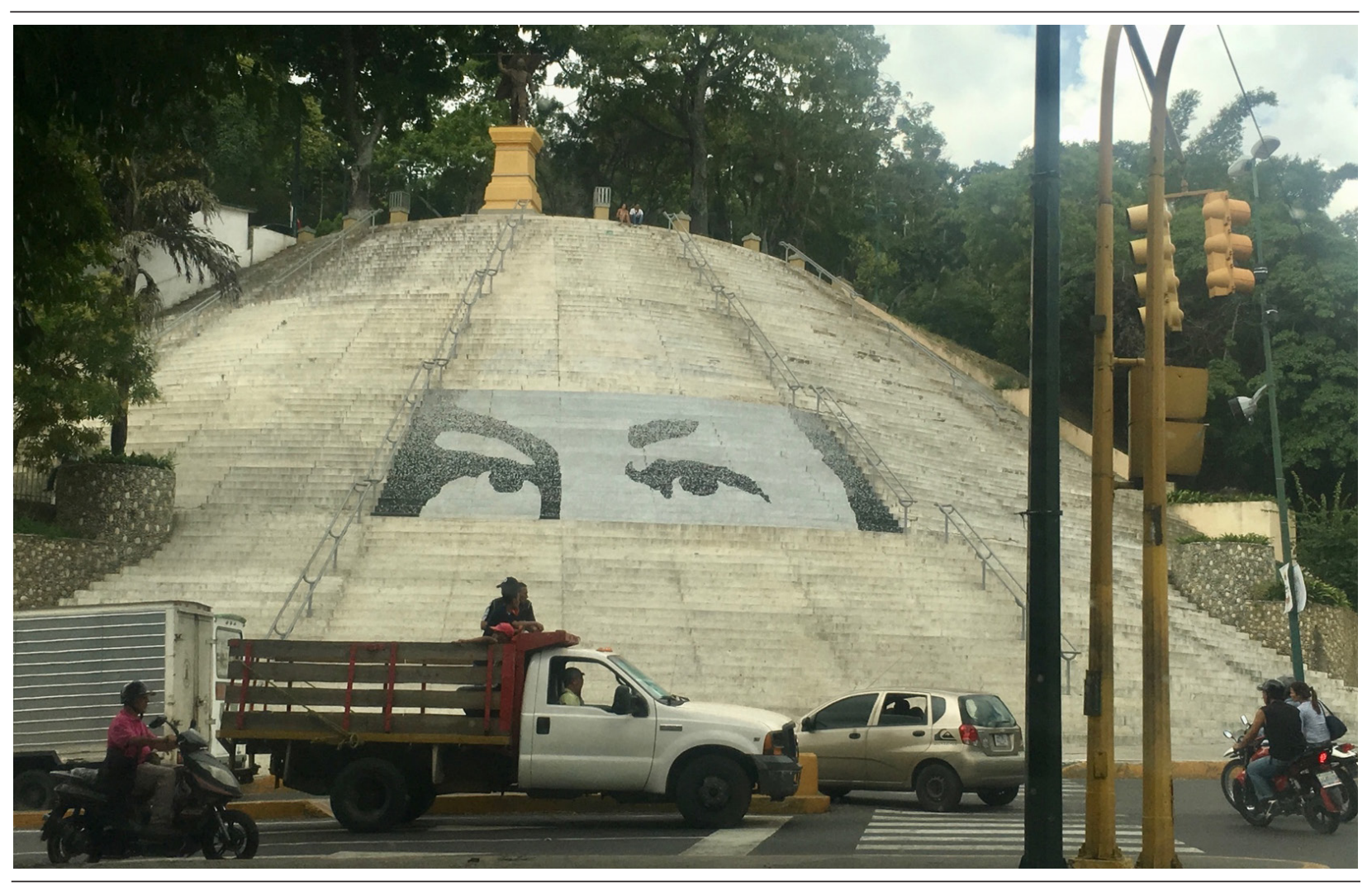

Figura 13. "Ojos de Chávez" en Las escaleras de El Calvario, municipio Libertador en Caracas. Coordenadas geográficas $10.50^{\circ} \mathrm{N} 66.92^{\circ} \mathrm{W}$. Fuente: elaboración propia (2019).

propaganda política" (Wilson 2021). Meses más tarde, el alcalde oficialista de municipio Libertador reafirmó esta intervención creando un mural indeleble hecho de mosaicos de cerámica blanco y negro (Figura 13). Esta acción podría leerse como mercadotecnia política o proselitismo al plasmar un vestigio político en el paisaje urbano y en la memoria de los transeúntes de la ciudad. (Wilson, 2021)

Durante varios años el mural estuvo protegido por cuerdas que impedían el paso, es decir, no se podían pisar los escalones donde estaban los “Ojos de Chávez". Parte de lo que se ha corroborado a través de las entrevistas cualitativas realizadas entre 2015 y 2020 , que respondían a nuestras preguntas sobre " $¿$ siente usted la influencia de la imagen de los "Ojos de Chávez" en su recorrido cotidiano por la ciudad?". A lo que algunos respondieron o confirmaron que una vez que quitaron las cuerdas, los transeúntes confirmaron que les resultaba difícil pisar los escalones por miedo a un tipo de represión o porque finalmente se sentían condicionados a no pisar la imagen (simbólica) que representaba la mirada de Chávez en el espacio urbano. Aunque no fuese su deseo, el condicionamiento y su impacto ya estaba creado. A través de este tipo de testimonio, podemos comprobar el efecto psicológico y la modificación de una práctica provocados por la fuerza de una imagen o símbolo político territorial movilizado en el espacio urbano. Una cantidad de personas describe la mirada de Chávez en el espacio público de 'invasiva' y a veces 'perturbadora', de alguna forma algunos habitantes manifiestan su desacuerdo, aunque serán siempre agradecidos de haber recibido una vivienda o como algunos mencionan "la casa de Chávez".

A una escala más pequeña pero no menos importante, constatamos la imagen de Chávez, su rostro, firma u ojos (Figura 14a), asimismo frases dichas por fallecido expresidente con su firma decoran las paredes de las áreas sociales y publicas del apartamento y de los edificios. La elaboración de estas pinturas, como fue indicado anteriormente, inspiradas principalmente por el arte pop de Andy Warhol, no es trivial ya que invoca el concepto de consumo masivo y repetitivo en esta expresión artística. $\mathrm{O}$ en diversos espacios públicos como en las taquillas de venta de tickets del metro (Figura 14b). 

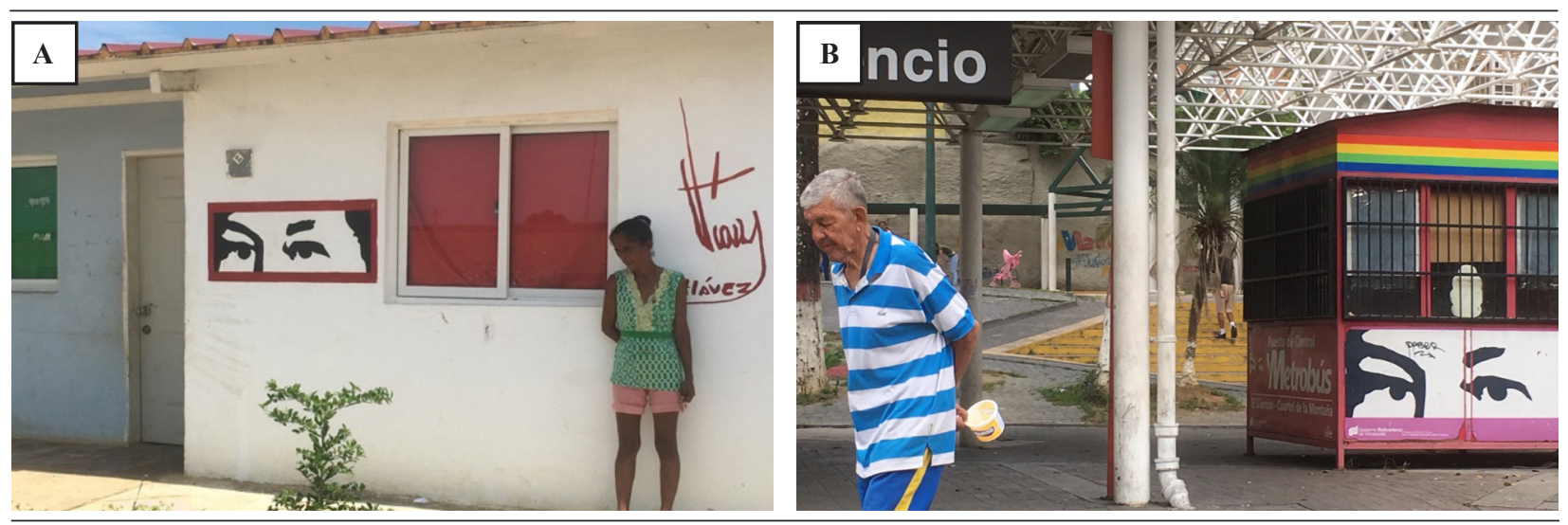

Figura 14a. Fachada vivienda individual GMVV

Figura 14b. Hombre pidiendo limosna, centro de Caracas-El Silencio. Fuente: elaboración propia (2019).

\section{Conclusión}

A modo de conclusión y retomando nuestras preguntas iniciales: ¿cómo, en este contexto político y socioeconómico, el Estado ha desarrollado este programa de producción de viviendas sociales?, ¿en qué medida este programa se inscribe en el terreno y propone nuevos instrumentos que respondan al cambio de los modos de vida de los habitantes? ¿La arquitectura y el tipo de edificios propuestos se corresponden con el ideal del socialismo del siglo XXI? Hemos comprobado que la política pública de construcción masiva de viviendas GMVV estaba inicialmente cargada de una importante voluntad política y social, sin embargo, su implementación en el tejido urbano es absolutamente arbitraria. Uno de los criterios para la incorporación de esta construcción masiva de viviendas consistió en incluir edificaciones en todos los espacios vacíos de la ciudad sin ningún tipo de planificación o criterios arquitectónicos y urbanísticos que dialogaran con el contexto existente. Lo que actualmente comienza a presentar un perfil y panorama de la ciudad en ciertos casos bastante lamentable. En términos de cifras y resultados, en abril de 2021, el Estado venezolano anunció que había logrado la construcción de 3.500 .000 viviendas GMVV y continúa con su propuesta de aumentar la construcción a 5 millones de viviendas sociales para el 2025. Si estimamos una tasa de ocupación de cuatro personas por apartamento, continuar esta producción masiva implicará que tres cuartas partes de la población vivirían en estas operaciones GMVV dentro de cuatro años. Una respuesta que parece tener poco sentido con la realidad de la geografía urbana existente en Venezuela y de una política pública desproporcionada con la actual realidad y necesidades de la sociedad venezolana.

Desde el punto de vista sociológico, nuestro estudio revela una dinámica creada entre el Estado y la población (una población o un pueblo completamente mitificado). Este último se siente protegido por el Estado al tener un hogar y de esta forma logra obtener un tipo de dignidad, sin embargo, la otra cara de la moneda es que el Estado espera o exige a cambio la lealtad del pueblo. Estas acciones pueden asociarse a "una expectativa común" y una relación de dependencia mayor entre los involucrados. Al mismo tiempo, según nuestro análisis, el hecho de observar la firma de Chávez tanto en las fachadas de las casas y de los edificios, así como al interior de los apartamentos, permite reconfirmar el deseo de mostrar a los habitantes que es el Estado quien simbólicamente sigue siendo el propietario.

El arquitecto Niño Araque defendió con insistencia la necesidad de repensar Caracas como un gran laboratorio abierto a la exploración. Por ello, cuestionamos la eficacidad de la integración del modelo de urbanización de este periodo revolucionario en el tejido existente. A la manera de Harvey, podemos concluir que la Gran Caracas y sus habitantes forman parte de un cuerpo que no está realmente sano y que debe ser diagnosticado con atención, su corazón late lentamente, con una presión arterial alta e incluso el flujo de sangre aún circula con las arterias deficientes. Desde esta perspectiva, parece pertinente decir que aún tenemos el gran desafío de pensar la reestructuración de la geografía urbana de Caracas que permita responder de una forma más adecuada a los traumas vividos por los habitantes y en su estructura física. Estos traumas, vinculados a la geografía urbana, a los riesgos climáticos, a la vulnerabilidad territorial, se inscriben en la memoria individual y colectiva de las personas como un producto de las políticas públicas propuestas por el Gobierno de turno. Todo ello creando una imagen instantánea de la Revolución Bolivariana o del socialismo del siglo XXI a través de la cotidianidad y de su impacto en el modo de vida de sus habitantes. 


\section{Referencias}

Andréani, F. (2013). Quand la révolution fait le mur : l'art mural vénézuélien entre imagination contestataire et contestation imaginaire. Cultures \& Conflits, 3(3-4), 123-139. https://doi.org/10.4000/conflits.18799

Azzellini, D. (2017). Communes and Workers' Control in Venezuela Building 21st Century Socialism from Below. Haymarket Books.

Barbarito, F., Fortis Silva, G., Villoria, N., Vielma, O., Pellicer, L. F., Sánchez, S. A., \& Mundarain, W. (2014). Rostros Y Rastros De Un Líder: Hugo Chávez. Memoria De Un Pueblo. Caracas, Venezuela: Centro Nacional de Historia, Archivo Nacional de la Nación.

Bernard, H. (2010). Regard sur l'image point-s de vue sur l'image... Regards \& impressions.

Brubaker, R. (2001). Au-delà de l'«identité». Actes de la recherche en sciences sociales, 4(139), 66-85. https:// doi.org/10.3917/arss.139.0066

Camou, A. (2001). Los desafios de la Gobernabilidad. Estudio preliminar y compilación. Flacso/IISUNAM/ Plaza y Valdés.

Cariola, C., Jungemann, B., \& Lacabana, M. (2012). Participaciónpopularytransformaciónsocioterritorial: las mesas técnicas de telecomunicaciones en Venezuela. Cuadernos del Cendes, 29(81), 79107. http://ve.scielo.org/scielo.php?script=sci arttext\&pid=S1012-25082012000300005\&lng=es\&t $\operatorname{lng}=\mathrm{es}$

Chauvin P. \& Reix F. (2015). Sociologies visuelles. Histoire et pistes de recherche. L'Année sociologique, 65(1), p. 15-41. https://doi.org/10.3917/ anso.151.0015

Chesneau, I. (2011). Abécédaire de Marcel Roncayolo. Entretiens. Infolio.

Du, M. \& Meyer, M. (2008). Photographier les paysages sociaux urbains. Itinéraires visuels dans la ville. ethnographiques.org, 17. L'éthique en anthropologie de la santé : conflits, pratiques, valeur heuristique [en ligne]. https://www.ethnographiques.org/2008/DuMeyer
Duque Corredor, R., Rondón, A., Álvarez, M., Gallardo, C., Saldarriaga, N., Brewer-Carías, A., \& Daniels, A. (2016). Coord. Louza Scognamiglio, L. La propiedad privada en Venezuela. Situación y perspectivas. FUNEDA Fundación Estudios de Derecho Administrativo.

Cariola, C. (coord.), B. Fernández, B. \& Jungemann, B. (2015). La Gran Misión Vivienda Venezuela : Hacia una política socio-territorial de vivienda. Una mirada desde la Caracas Metropolitana. Cendes-Fundacredesa, Fondo Editorial Méndez Castellanos. http://www. ucv.ve/fileadmin/user_upload/cendes/Libro_Mision_ Vivienda/AF_MisionViviendadigital.pdf

Giordani, J. (2014). Testimonio y responsabilidad ante la historia. Aporrea. https:/www.aporrea.org/ideologia/ a190011.html

Harvey, D. (2011). Le capitalisme contre le droit à la ville. Néolibéralisme, urbanisation, résistances. Editions Amsterdam.

Lander, E. (2005). Venezuelan Social Conflict in a Global Context. Latin American Perspectives, 32(2), 20-38. https://doi.org/10.1177/0094582X04273867

Lander, E. (2007). El Estado y las tensiones de la participación popular en Venezuela. OSAL (CLACSO), Año VIII, 22. http://biblioteca.clacso. edu.ar/ar/libros/osal/osal22/D22Lander.pdf

Lefebvre, H. (2013). La producción del espacio. Capitán Swing Libros, S. L.

Levy, J. \& Lussault, M. (2003). Dictionnaire de la géographie et de l'espace des sociétés. Belin.

López Maya, M. (2012). Participación y poder popular en Venezuela : antes y ahora. Universidad Central de Venezuela. Revista Historia, 3(3), 53-77. https:// produccioncientificaluz.org/index.php/historia/ article/view/14628

Mauss, M. (2013). Sociologie et anthropologie. Presse Universitaire de France (Quadrige).

Maresca, S. \& Meyer, M. (2013). Précis de photographie à l'usage des sociologues, Rennes, Presses universitaires de Rennes. 
Merlin, P. (1989). Morphologie urbaine et parcellaire, Saint-Denis, Presses Universitaires de Vincennes.

Molina Loyola, M. E. (2020). Arte urbano, política y memoria en 2019: Primeros pasos hacia la conformación de un archivo del muralismo político en Santiago de Chile.e-Ciencias de la Información, 10(1), 298-313. https://doi.org/10.15517/eci.v10i1.37277

Nelson, R. A. (1996). A Chronology and Glossary of Propaganda in the United States. Greenwood Press.

Niño Araque, W. (2005). Metrópolis, megalópolis, el mapa desbordado de Caracas. En VV.AA., Caracas Cenital (pp. 16 - 30). Criteria Editorial, C.A.

Ortega Olivares, M. (2009). Metodología de la sociología visual y su correlato etnológico. Argumentos, 22(59), 165-184. http://www.scielo.org. $\mathrm{mx} / \mathrm{scielo}$.php? script=sci arttext\&pid=S0187-57952009000100006\&lng=es\&tln $\mathrm{g}=\mathrm{es}$

Piette, A. (2007). Fondements épistémologiques de la photographie. Ethnologie française, 37(1), 2328. https://doi.org/10.3917/ethn.071.0023

Ruiz-Tagle, J. (2016). La segregación y la integración en la sociología urbana: revisión de enfoques y aproximaciones críticas para las políticas públicas. Revista INVI, 31(87), 9-57. http://dx.doi. org/10.4067/S0718-83582016000200001

Tarragoni, F. (2016). Le peuple est dans la rue. Politiques du street art dans les barrios vénézuéliens. Sociologie de l'Art, 1(1-2), 129-151. https://doi.org/10.3917/ soart.025.0129

Torres, A., Pineda, V. \& Rey, E. (2017). Las disputas urbanas en la Caracas del siglo XXI: retos y potencialidades en la producción social del suelo. Territorios, 36,47-68. https://doi.org/10.12804/ revistas.urosario.edu.co/territorios/a.4845

Valdez Zepeda, A. \& Huerta Franco, D.A. (2020). Desastres naturales y cambios políticos: Alternancia política electoral en América Latina. Revista Venezolana de Gerencia, 25(3), 421-436. https://doi. org/10.37960/rvg.v25i3.33381
Vásquez Romero, J. E., (2014). Marketing político de izquierda en América Latina: el chavismo como experiencia exitosa. Revista Caribeña de Ciencias Sociales. https://www.eumed.net/rev/caribe/2014/03/ marketing-politico-izquierda.pdf

Vásquez, P. (2014). Le Chavisme. Un militarisme compassionnel. Editions de la Maison des Sciences de l'Homme (Le (bien) commun).

Wagner, J. (2006). Visible materials, visualised theory and images of social research. Visual Studies, 21(1), 5569, http://doi.org/10.1080/14725860600613238

Wilson, Y. (2020). Le logement social au XXIe siècle au Venezuela : l'État après la catastrophe. Les Cahiers de la recherche architecturale urbaine et paysagère, 8. https://doi.org/10.4000/craup.4903

Wilson, Y. (2021). The Eyes of Chávez. Social Housing as Monument and Image. ReVista, the Harvard Review of Latin America. David Rockefeller Center for Latin American Studies https://revista.drclas. harvard.edu/author/yaneira-wilson-wetter/ 